\title{
SYNTHESIS, CRYSTAL STRUCTURE AND ANTIMICROBIAL ACTIVITY OF A HETERO TRINUCLEAR MANGANESE(III)-IRON(II) COMPLEX DERIVED FROM N,N'-BIS(5-METHYLSALICYLIDENE)-1,2-DIAMINOETHANE
}

\author{
Xiao-Ming Hu, Ling-Wei Xue ${ }^{*}$, Gan-Qing Zhao and Wei-Chun Yang \\ College of Chemistry and Chemical Engineering, Pingdingshan University, Pingdingshan \\ Henan, 467000, China
}

(Received October 22, 2014; revised September 5, 2015)

\begin{abstract}
A new hetero trinuclear manganese(III)-iron(II) complex, $\left[\mathrm{Mn}(\mathrm{salen})\left(\mathrm{H}_{2} \mathrm{O}\right)\right]_{2}\left[\mathrm{Fe}(\mathrm{CN})_{6}\right]$, in which salen is the dianionic form of $\mathrm{N}^{\mathrm{N}} \mathrm{N}^{\prime}$-bis(5-methylsalicylidene)-1,2-diaminoethane, has been prepared and characterized by elemental analyses, IR, and single crystal X-ray crystallographic determination. The crystal of the complex is monoclinic: space group $P 2_{1} / c, a=10.768(2), b=14.248(3), c=15.222(3) \AA, \beta=95.394(2)^{\circ}, V=$ $2325.0(8) \AA^{3}, Z=2, R_{1}=0.0754, w R_{2}=0.2366$. The bis-Schiff base ligand coordinates to the $\mathrm{Mn}$ atom through phenolate $\mathrm{O}$ and imine $\mathrm{N}$ atoms. Each $\mathrm{Mn}$ atom in the complex is in octahedral coordination, with the equatorial donor atoms come from the Schiff base ligand, and with the axial donor atoms come from a water $\mathrm{O}$ atom and a cyanide $\mathrm{N}$ atom. The effects of the complex on the antimicrobial activity against Staphylococcus aureus, Escherichia coli, and Candida albicans were studied.
\end{abstract}

KEY WORDS: Schiff base, Manganese(III) complex, Iron(II) complex, Heteronuclear, Crystal structure

\section{INTRODUCTION}

Schiff bases are a kind of important ligands in coordination chemistry and have extensive application in many fields [1-3]. Schiff bases derived from aromatic carbonyl compounds have been widely studied in connection with metalloprotein models and asymmetric catalysis, due to the versatility of their steric and electronic properties. Schiff bases and their biologically active complexes have been often used as chelating ligands in the coordination chemistry of transition metals as radiopharmaceuticals for cancer targeting, agrochemicals, as model systems for biological macromolecules, as catalysts and as dioxygen carriers [4-7]. In recent years, metal complexes of Schiff bases have attracted dramatically attention due to their versatile biological activity, such as antifungal, antibacterial and antitumor [8-10]. It has been shown that the Schiff base complexes derived from salicylaldehyde and its derivatives with primary amines, bearing the $\mathrm{N}_{2} \mathrm{O}, \mathrm{N}_{2} \mathrm{~S}, \mathrm{NO}_{2}$ or NSO donor sets, have interesting biological activity [11-14]. In addition, the molecular design of extended structures starting from molecular precursors is of great interest. A preferred way to construct such materials is to use ionic building blocks in which one unit contains a potential bridging ligand and another contains a potential coordination site [15]. In the present paper, the preparation, characterization and antimicrobial activity of a new hetero trinuclear manganese(III)-iron(II) complex, $\left[\mathrm{Mn}(\text { salen })\left(\mathrm{H}_{2} \mathrm{O}\right)\right]_{2}\left[\mathrm{Fe}(\mathrm{CN})_{6}\right]$, in which salen is the dianionic form of N,N'-bis(5-methylsalicylidene)-1,2-diaminoethane $\left(\mathrm{H}_{2} \mathrm{salen}\right)$, is reported.

\section{EXPERIMENTAL}

\section{Material and methods}

5-Methylsalicylaldehyde and ethane-1,2-diamine were purchased from Fluka. Other reagents and solvents were analytical grade and used without further purification. Elemental $(\mathrm{C}, \mathrm{H}$, and

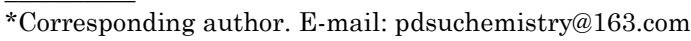


N) analyses were made on a PerkinElmer Model 240B automatic analyser. Infrared (IR) spectra were recorded on an IR-408 Shimadzu 568 spectrophotometer. X-ray diffraction was carried out on a Bruker SMART 1000 CCD area diffractometer.

\section{Synthesis of the complex}

5-Methylsalicylaldehyde $(0.272 \mathrm{~g}, 2 \mathrm{mmol})$ and ethane-1,2-diamine $(0.060 \mathrm{~g}, 1 \mathrm{mmol})$ were reacted in methanol $(30 \mathrm{~mL})$ at ambient temperature for $1 \mathrm{~h}$. Then, manganese perchlorate hexahydrate $(0.362 \mathrm{~g}, 1 \mathrm{mmol})$ was added to the mixture. The mixture was further stirred at room temperature for $30 \mathrm{~min}$ to give a deep brown solution. The methanol solution was carefully layered on the top of an aqueous solution $(20 \mathrm{~mL})$ of $\mathrm{K}_{4}\left[\mathrm{Fe}(\mathrm{CN})_{6}\right] \cdot 3 \mathrm{H}_{2} \mathrm{O}(0.422 \mathrm{~g}, 1$ $\mathrm{mmol}$ ) in a test tube. Deep brown single crystals of the complex, suitable for single crystal Xray diffraction, were formed after a few days. Yield, $323 \mathrm{mg}$. Analysis calc. (\%) for $\mathrm{C}_{42} \mathrm{H}_{40} \mathrm{FeMn}_{2} \mathrm{~N}_{10} \mathrm{O}_{6}$ : C, 53.29; H, 4.26; N, 14.80. Found (\%): C, 53.03; H, 4.41; N, 14.66. Selected IR data $\left(v, \mathrm{~cm}^{-1}\right): 2027 \mathrm{~s}, v\left(\mathrm{~N}_{3}\right), 1632 \mathrm{~s}, v(\mathrm{C}=\mathrm{N})$.

Table 1. Crystallographic data and experimental details for the complex.

\begin{tabular}{|l|l|}
\hline Parameter & Value \\
\hline Habit; color & Block; deep brown \\
\hline Formula & $\mathrm{C}_{42} \mathrm{H}_{40} \mathrm{FeMn}_{2} \mathrm{~N}_{10} \mathrm{O}_{6}$ \\
\hline Formula weight & 946.6 \\
\hline Temperature, $\mathrm{K}$ & $298(2)$ \\
\hline Crystal size, $\mathrm{mm}$ & $0.17 \times 0.17 \times 0.13$ \\
\hline Radiation $(\lambda, \AA)$ & Mo $K_{\alpha}(0.71073)$ \\
\hline Crystal system & Monoclinic \\
\hline Space group & $P 2_{1} / c$ \\
\hline Unit cell dimensions: & \\
\hline$a, \AA$ & $10.768(2)$ \\
\hline$b, \AA$ & $14.248(3)$ \\
\hline$c, \AA$ & $15.222(3)$ \\
\hline$\beta$, deg & $95.394(2)$ \\
\hline$V, \AA^{3}$ & $2325.0(8)$ \\
\hline$Z$ & 2 \\
\hline$\rho_{\text {calcd, }}$ g cm & \\
\hline$F(000)$ & 1.352 \\
\hline Absorption coefficient, $\mathrm{mm}^{-1}$ & 972 \\
\hline$\theta$ Range for data collection, deg & 0.897 \\
\hline Index ranges, $h, k, l$ & $2.38-25.20$ \\
\hline Reflections collected & $-12 \leq h \leq 12 ;-17 \leq k \leq 17 ;-18 \leq l \leq 17$ \\
\hline Independent reflections $\left(R_{\text {int }}\right)$ & 21089 \\
\hline Reflections with $I>2 \sigma(I)$ & $4169(0.0607)$ \\
\hline Parameters & 2798 \\
\hline Restraints & 285 \\
\hline Goodness-of-fit on $F^{2}$ & 3 \\
\hline Final $R$ indices $(I>2 \sigma(I))$ & 1.090 \\
\hline$R$ indices $($ all data $)$ & $R_{1}=0.0754, w R_{2}=0.2366$ \\
\hline Largest difference peak and hole, $e \AA^{-3}$ & $R_{1}=0.1207, w R_{2}=0.2674$ \\
\hline & $1.054,-0.332$ \\
\hline & \\
\hline
\end{tabular}

\section{$X$-ray diffraction}

Data were collected from a selected crystal mounted on a thin glass fiber. The data for the complex were processed with SAINT [16] and corrected for absorption using SADABS [17]. 
Multi-scan absorption corrections were applied with $\psi$-scans [18]. The structure was solved by direct method using the program SHELXS-97 and refined by full-matrix least-squares techniques on $F^{2}$ using anisotropic displacement parameters [19]. The water hydrogen atoms were located from a difference Fourier map and refined isotropically, with $\mathrm{O}-\mathrm{H}$ and $\mathrm{H} \cdots \mathrm{H}$ distances restrained to $0.85(1)$ and $1.37(2) \AA$, respectively. The remaining hydrogen atoms were placed at the calculated positions. Idealized $\mathrm{H}$ atoms were refined with isotropic displacement parameters set to 1.2 (1.5 for methyl groups) times the equivalent isotropic $U$ values of the parent carbon atoms. The crystallographic data for the complexes are listed in Table 1.

Supplementary material has been deposited with the Cambridge Crystallographic Data Centre (no.1024665; deposit@ccdc.cam.ac.uk or http://www.ccdc.cam.ac.uk).

\section{RESULTS AND DISCUSSION}

The Schiff base $\mathrm{H}_{2}$ salen was readily prepared by the condensation of 1:2 molar ratio of ethane1,2-diamine with 5-methylsalicylaldehyde in methanol at ambient temperature. The Schiff base was not isolated and used directly to the synthesis of the complex with $\mathrm{K}_{4}\left[\mathrm{Fe}(\mathrm{CN})_{6}\right] \cdot 3 \mathrm{H}_{2} \mathrm{O}$. Crystals of the complex are very stable at room temperature. The results of the elemental analyses are in accord with the composition suggested for the complex.

\section{Infrared spectra}

In order to compare the IR spectrum of the complex with the free Schiff base, small quantity of $\mathrm{H}_{2}$ salen was prepared. The IR spectrum of the Schiff base contains medium $\mathrm{C}-\mathrm{O}$ absorption band at $1237 \mathrm{~cm}^{-1}$. The band disappeared on complexation, and new $\mathrm{C}-\mathrm{O}$ absorption band appeared at $1086 \mathrm{~cm}^{-1}$ in the spectrum of the complex, indicating that the Schiff base coordinates to the metal atom through deprotonated form. The infrared spectrum of the complex displays intense absorption band at $1615 \mathrm{~cm}^{-1}$, which can be assigned to the $\mathrm{C}=\mathrm{N}$ stretching frequencies of the Schiff base ligand, whereas for the free Schiff base the corresponding absorption band is observed at higher wavenumber, $1632 \mathrm{~cm}^{-1}$. The shift of the band on complexation indicates the coordination of the imine nitrogen to the metal center [20]. In the spectrum of the complex, strong bands observed at 2155 and $2143 \mathrm{~cm}^{-1}$ are assigned to the absorptions of the non-bridging and bridging cyanide groups [21], and weak and broad band centered at $3318 \mathrm{~cm}^{-1}$ is assigned to the water $\mathrm{O}-\mathrm{H}$ vibration.

\section{Crystal structure description}

The molecular structure of the complex is shown in Figure 1. Selected bond distances and angles are listed in Table 2. The complex is a cyano-bridged heteronuclear manganese (III)iron(II) species, with $\mathrm{Mn} \cdots \mathrm{Fe}$ separation of 5.210(2) $\AA$. The Mn atom in the complex is coordinated by two phenolate $\mathrm{O}$ and two imine $\mathrm{N}$ atoms of the Schiff base ligand, defining the equatorial plane, and by one water $\mathrm{O}$ atom and one cyanide $\mathrm{N}$ atom, occupying the two axial positions, generating an octahedral geometry. The two axial bonds are much longer than the basal bonds, which is caused by the Jahn-Teller effects. The bond distances subtended at the Mn atoms are comparable to those observed in similar manganese (III) complexes with Schiff bases [22-24]. The dihedral angle between the two benzene rings of the Schiff base ligand is $7.0(3)^{\circ}$. The $\mathrm{Fe}$ atom in the complex is coordinated by six $\mathrm{C}$ atoms from cyanide ligands, generating an octahedral geometry. The bond distances subtended at the $\mathrm{Fe}$ atom are comparable to those observed in similar complexes with Fe-C bonds [22-24].

In the crystal structure of the complex, the $\left[\mathrm{Mn}(\mathrm{salen})\left(\mathrm{H}_{2} \mathrm{O}\right)\right]$ moieties are linked by a $\left[\mathrm{Fe}(\mathrm{CN})_{6}\right]$ core. The hetero trinuclear complex molecules are further linked through intermolecular $\mathrm{O}-\mathrm{H} \cdots \mathrm{O}$ and $\mathrm{O}-\mathrm{H} \cdots \mathrm{N}$ hydrogen bonds (Table 3), generating $1 \mathrm{D}$ chains along 
the axis-c direction (Figure 2). There are $\pi \cdots \pi$ interactions among the chains in the axis- $b$ direction, with a centroid (C1-C6) - centroid (C11-C16) distance of 3.799(2) A.

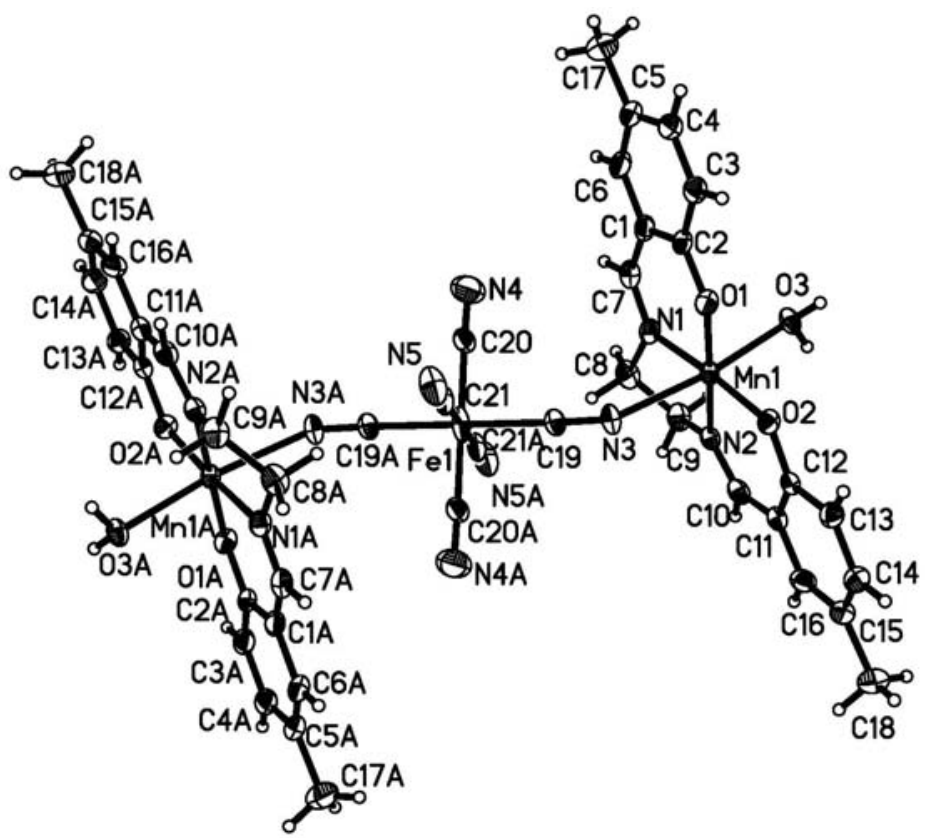

Figure 1. Perspective view of the complex with $30 \%$ probability thermal ellipsoids. Atoms labelled with the suffix A are at the symmetry position $2-x, 1-y, 1-z$.

Table 2. Selected bond distances $(\AA)$ and angles (deg) for the complex* .

\begin{tabular}{|l|l|l|l|}
\hline Bond lengths & & & \\
\hline $\mathrm{Fe}(1)-\mathrm{C}(20)$ & $1.801(8)$ & $\mathrm{Fe}(1)-\mathrm{C}(21)$ & $1.930(8)$ \\
\hline $\mathrm{Fe}(1)-\mathrm{C}(19)$ & $1.939(7)$ & $\mathrm{Mn}(1)-\mathrm{O}(1)$ & $1.858(5)$ \\
\hline $\mathrm{Mn}(1)-\mathrm{O}(2)$ & $1.878(4)$ & $\mathrm{Mn}(1)-\mathrm{N}(1)$ & $1.972(5)$ \\
\hline $\mathrm{Mn}(1)-\mathrm{N}(2)$ & $1.986(5)$ & $\mathrm{Mn}(1)-\mathrm{N}(3)$ & $2.363(6)$ \\
\hline $\mathrm{Mn}(1)-\mathrm{O}(3)$ & $2.273(5)$ & & \\
\hline $\mathrm{Bond}$ angles & & $\mathrm{C}(20)-\mathrm{Fe}(1)-\mathrm{C}(21 \mathrm{~A})$ & $89.5(3)$ \\
\hline $\mathrm{C}(20)-\mathrm{Fe}(1)-\mathrm{C}(20 \mathrm{~A})$ & 180 & $\mathrm{C}(21)-\mathrm{Fe}(1)-\mathrm{C}(21 \mathrm{~A})$ & 180 \\
\hline $\mathrm{C}(20)-\mathrm{Fe}(1)-\mathrm{C}(21)$ & $90.5(3)$ & $\mathrm{C}(20)-\mathrm{Fe}(1)-\mathrm{C}(19 \mathrm{~A})$ & $90.8(3)$ \\
\hline $\mathrm{C}(20)-\mathrm{Fe}(1)-\mathrm{C}(19)$ & $89.2(3)$ & $\mathrm{C}(21)-\mathrm{Fe}(1)-\mathrm{C}(19)$ & $89.9(3)$ \\
\hline $\mathrm{C}(21)-\mathrm{Fe}(1)-\mathrm{C}(19 \mathrm{~A})$ & $90.1(3)$ & $\mathrm{O}(1)-\mathrm{Mn}(1)-\mathrm{O}(2)$ & $92.5(2)$ \\
\hline $\mathrm{C}(19)-\mathrm{Fe}(1)-\mathrm{C}(19 \mathrm{~A})$ & 180 & $\mathrm{O}(2)-\mathrm{Mn}(1)-\mathrm{N}(1)$ & $174.6(2)$ \\
\hline $\mathrm{O}(1)-\mathrm{Mn}(1)-\mathrm{N}(1)$ & $92.8(2)$ & $\mathrm{O}(2)-\mathrm{Mn}(1)-\mathrm{N}(2)$ & $92.5(2)$ \\
\hline $\mathrm{O}(1)-\mathrm{Mn}(1)-\mathrm{N}(2)$ & $\mathrm{O}(1)-\mathrm{Mn}(1)-\mathrm{O}(3)$ & $88.74(19)$ \\
\hline $\mathrm{N}(1)-\mathrm{Mn}(1)-\mathrm{N}(2)$ & $\mathrm{N}(1)-\mathrm{Mn}(1)-\mathrm{O}(3)$ & $87.2(2)$ \\
\hline $\mathrm{O}(2)-\mathrm{Mn}(1)-\mathrm{O}(3)$ & $\mathrm{O}(1)-\mathrm{Mn}(1)-\mathrm{N}(3)$ & $92.0(2)$ \\
\hline $\mathrm{N}(2)-\mathrm{Mn}(1)-\mathrm{O}(3)$ & $\mathrm{N}(1)-\mathrm{Mn}(1)-\mathrm{N}(3)$ & $82.7(2)$ \\
\hline $\mathrm{O}(2)-\mathrm{Mn}(1)-\mathrm{N}(3)$ & $\mathrm{O}(3)-\mathrm{Mn}(1)-\mathrm{N}(3)$ & $169.9(2)$ \\
\hline $\mathrm{N}(2)-\mathrm{Mn}(1)-\mathrm{N}(3)$ & $94.05(19)$ & & \\
\hline
\end{tabular}

* Symmetry code for A: $2-x, 1-y, 1-z$. 
Table 3. Hydrogen geometries for the complex.

\begin{tabular}{|c|c|c|c|c|}
\hline$D-\mathrm{H} \cdots A$ & $\mathrm{~d}(D-\mathrm{H}, \AA)$ & $\mathrm{d}(\mathrm{H} \cdots A, \AA)$ & $\mathrm{d}(D \cdots A, \AA)$ & $\omega(D-\mathrm{H} \cdots A, \mathrm{deg})$ \\
\hline $\mathrm{O}(3)-\mathrm{H}(3 \mathrm{~A}) \cdots \mathrm{O}(2)^{\mathrm{i}}$ & $0.85(1)$ & $2.03(2)$ & $2.854(6)$ & $165(8)$ \\
\hline $\mathrm{O}(3)-\mathrm{H}(3 \mathrm{~B}) \cdots \mathrm{N}(5)^{\mathrm{II}}$ & $0.85(1)$ & $2.00(2)$ & $2.830(8)$ & $167(8)$ \\
\hline
\end{tabular}

Symmetry codes : (i) $2-x, 1-y,-z$; (ii) $2-x,-1 / 2+y, 1 / 2-z$.

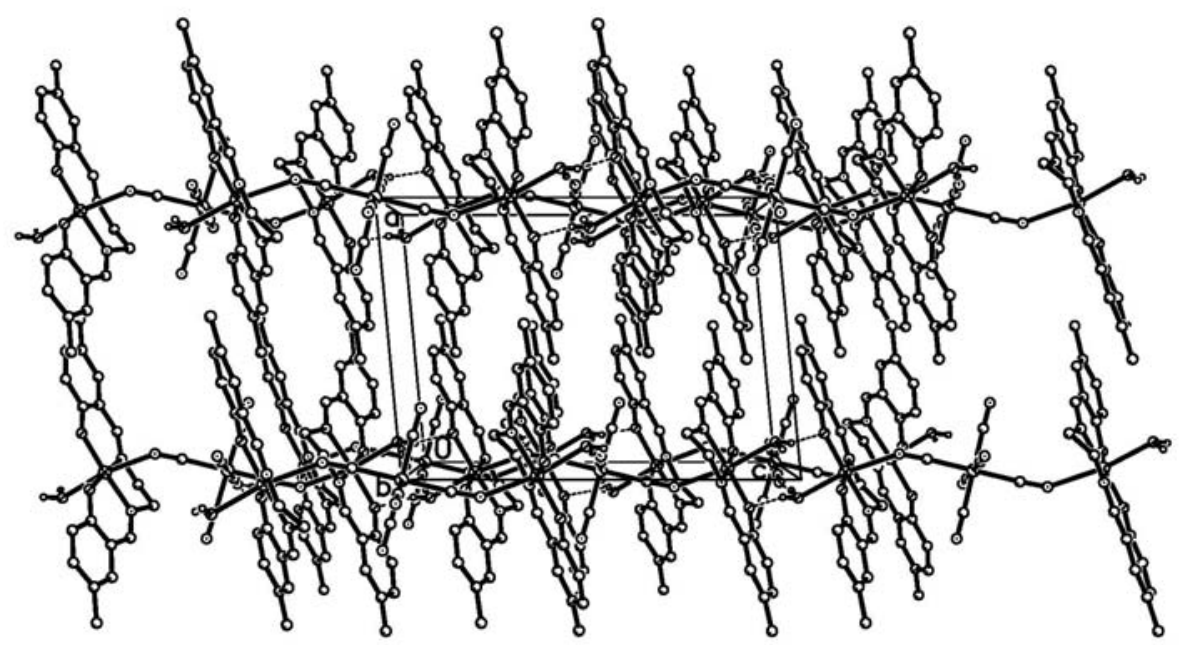

Figure 2. Molecular packing structure of the complex.

\section{Antimicrobial activity}

Qualitative determination of antimicrobial activity was done using the disk diffusion method [25-27]. The results are summarized in Table 4. A comparative study of minimum inhibitory concentration (MIC) values of the free Schiff base and the complex indicated that the complex has more effective activity than the free Schiff base. Generally, this is caused by the greater lipophilic nature of the complexes than the ligands. Such increased activity of the metal chelates can be explained on the basis of chelating theory $[28,29]$. On chelating, the polarity of the metal atoms will be reduced to a greater extent due to the overlap of the ligand orbital and partial sharing of positive charge of the metal atoms with donor atoms. Further, it increases the delocalization of $p$-electrons over the whole chelate ring and enhances the lipophilicity of the complexes. This increased lipophilicity enhances the penetration of the complexes into lipid membrane and blocks the metal binding sites on enzymes of micro-organisms.

From Table 4, it can be seen that the complex has greater antibacterial and antifungal activities against Escherichia coli and Candida albicans when compared to the reference drug tetracycline. But, for Staphylococcus aureus, the activity of the complex is much weak.

Table 4. MIC values $(\mu \mathrm{g} / \mathrm{mL})$ for the antimicrobial activities of the tested compounds.

\begin{tabular}{|c|c|c|c|}
\hline Compound & Staphylococcus aureus & Escherichia coli & Candida albicans \\
\hline $\mathrm{H}_{2}$ salen & 128 & 512 & $>1024$ \\
\hline The complex & 16.0 & 2.0 & 128 \\
\hline Tetracycline & 0.30 & 2.15 & $>1024$ \\
\hline
\end{tabular}




\section{CONCLUSION}

In summary, a new hetero trinuclear manganese(III)-iron(II) complex derived from the bisSchiff base ligand N,N'-bis(5-methylsalicylidene)-1,2-diaminoethane has been prepared and characterized. The crystal structure of the complex was confirmed by X-ray single crystal structure determination. The $\mathrm{Mn}$ and $\mathrm{Fe}$ atoms in the complex are in octahedral coordination. The biological test showed that the complex has effective activities against Escherichia coli and Candida albicans.

\section{ACKNOWLEDGMENTS}

This research was supported by the National Sciences Foundation of China (No. 20676057 and 20877036) and Top-class foundation of Pingdingshan University (No. 2008010).

\section{REFERENCES}

1. Pradeep, C.P.; Das, S.K. Coord. Chem. Rev. 2013, 257, 1699.

2. Alhadi, A.A.; Shaker, S.A.; Yehye, W.A.; Ali, H.M.; Abdullah, M.A. Bull. Chem. Soc. Ethiop. 2012, 26, 95.

3. Moradi-Shoeili, Z.; Amini, Z.; Boghaei, D.M.; Notash, B. Polyhedron 2013, 53, 76.

4. Habibi, M.H.; Montazerozohori, M.; Lalegani, A.; Harrington, R.W.; Clegg, W. J. Fluorine Chem. 2006, 127, 769.

5. Unaleroglu, C.; Temelli, B.; Hokelek, T. J. Mol. Struct. 2001, 570, 91.

6. Blower, P.J. Transition Met. Chem. 1998, 23, 109.

7. Berkessel, A.; Frauenkon, M.; Schwenkreis, T.; Steinmetz, J. Mol. Catal. A: Chem. 1997, 117, 339 .

8. Cinarli, A.; Gurbuz, D.; Tavman, A.; Birteksoz, A.S. Bull. Chem. Soc. Ethiop. 2011, 25, 407.

9. Yaul, A.R.; Dhande, V.V.; Pethe, G.B.; Aswar, A.S. Bull. Chem. Soc. Ethiop. 2014, 28, 255.

10. Mukherjee, T.; Pessoa, J.C.; Kumar, A.; Sarkar, A.R. Dalton Trans. 2013, 42, 2594.

11. Yuan, C.X.; Lu, L.P.; Gao, X.L.; Wu, Y.B.; Guo, M.L.; Li, Y.; Fu, X.Q.; Zhu, M.L. J. Biol. Inorg. Chem. 2009, 14, 841.

12. Sonmez, M.; Celebi, M.; Berber, I. Eur. J. Med. Chem. 2010, 45, 1935.

13. Xue, L.W.; Zhao, G.Q.; Han, Y.J.; Feng, Y.X. Russ. J. Coord. Chem. 2011, 37, 262.

14. Xue, L.W.; Han, Y.J.; Zhao, G.Q.; Feng, Y.X. Russ. J. Coord. Chem. 2012, 38, 24.

15. Miyasaka, H.; Matsumoto, N.; Re, N.; Gallo, E.; Floriani, C. Inorg. Chem. 1997, 36, 670.

16. Bruker, SMART and SAINT. Bruker AXS Inc.: Madison, Wisconsin, USA; 2002.

17. Sheldrick, G.M. SADABS. Program for Empirical Absorption Correction of Area Detector, University of Göttingen: Germany; 1996.

18. North, A.C.T.; Phillips, D.C.; Mathews, F.S. Acta Crystallogr. A 1968, $24,351$.

19. Sheldrick, G.M. SHELXTL V5.1 Software Reference Manual, Bruker AXS, Inc.: Madison, Wisconsin, USA; 1997.

20. Lal, R.A.; Choudhury, S.; Ahmed, A.; Chakraborty, M.; Borthakur, R.; Kumar, A. J. Coord. Chem. 2009, 62, 3864.

21. Zhang, D.P.; Wang, H.L.; Chen, Y.T.; Ni, Z.H.; Tian, L.J.; Jiang, J.Z. Inorg. Chem. 2009, $48,11215$.

22. Glaser, T.; Hefdemeier, M.; Krickemeyer, E.; Bogge, H.; Stammler, A.; Frohlich, R.; Bill, E.; Schnack, J. Inorg. Chem. 2009, 48, 607.

23. Miyasaka, H.; Matsumoto, N.; Okawa, H.; Gallo, E.; Floriani, C. J. Am. Chem. Soc. 1996, $118,981$. 
24. Clemente-Leon, M.; Coronado, E.; Galan-Mascaros, J.R.; Gomez-Garcia, C.J.; Woike, T.; Clemente-Juan, J.M. Inorg. Chem. 2001, 40, 87.

25. Bauer, A.W.; Kirby, W.W.M.; Sherris, J.C.; Turck, M. Am. J. Clin. Pathol. 1966, 45, 493.

26. Barry, A. Procedures and Theoretical Considerations for Testing Antimicrobial Agents in Agar Media, in Antibiotics in Laboratory Medicine, Lorian, V. (Ed.), Williams and Wilkins: Baltimore; 1991.

27. Rosu, T.; Negoiu, M.; Pasculescu, S.; Pahontu, E.; Poirier, D.; Gulea, A. Eur. J. Med. Chem. 2010, 45, 774.

28. Searl, J.W.; Smith, R.C.; Wyard, S. J. Proc. Phys. Soc. 1961, 78, 1174.

29. Tweedy, B.G. Phytopathology 1946, 55, 910. 